\title{
Substituting otoliths for chemical analyses: Does sagitta = lapillus?
}

\author{
Nathan G. Smith*, Cynthia M. Jones \\ Center for Quantitative Fisheries Ecology, Old Dominion University, 800 W 46th St., Norfolk, Virginia 23508, USA
}

\begin{abstract}
Chemical analysis of fish otoliths has become an important technique in fisheries science with widespread applications. Most research up to this point has focused predominantly on sagittal otoliths, but the underlying assumptions may also apply to lapilli. The goal of this study was to determine whether lapilli and sagittae have the same otolith chemistry and whether one can be substituted for the other for solution-based chemical analysis in wild-captured fish. We compared the stable isotope chemistry $\left(\delta^{13} \mathrm{C}\right.$ and $\left.\delta^{18} \mathrm{O}\right)$ of paired sagittae and lapilli of juvenile spotted seatrout Cynoscion nebulosus collected from Chesapeake Bay seagrass beds in 2002. Stable isotopic signatures were significantly different in both carbon and oxygen for paired sagittae and lapilli. Both $\delta^{13} \mathrm{C}$ and $\delta^{18} \mathrm{O}$ values were higher in the sagitta relative to the lapillus. As a correlate to isotopic analysis, shape measurements were taken on paired sagittae and lapilli for growth comparison. While the 2 otoliths are a similar size at formation, the sagitta grows faster, quickly outgrowing the lapillus during the juvenile stage. We expected that after detrending isotope data to account for fish length, the relation with otolith growth would become clear. Surprisingly, this was not true for either $\delta^{13} \mathrm{C}$ or $\delta^{18} \mathrm{O}$. Carbon isotopic differences appear to be strongly influenced by metabolism, and the relationship of $\delta^{18} \mathrm{O}$ with otolith growth is obscured by a variable environment. Our results clearly show that sagittae is not equal to lapilli for solution-based whole otolith analysis. Moreover, while the sagitta reflects the juvenile stage environment with greater fidelity, the lapillus reflects the larval stage more strongly.
\end{abstract}

KEY WORDS: Otolith chemistry $\cdot$ Sagitta $\cdot$ Lapillus $\cdot$ Stable isotopes Resale or republication not permitted without written consent of the publisher

\section{INTRODUCTION}

Fish otoliths can provide a record of the environment a fish has inhabited through chemical analyses. Techniques and applications for these analyses have been rapidly expanding in fisheries science for the past decade (e.g. Campana 1999). Recently, many techniques have been developed (e.g. micromilling, laser ablation inductively coupled plasma mass spectrometry [LA-ICPMS]) that allow fine-scale sampling of otolith sections where sampling can occur on a weekly or even subweekly basis. However, these techniques are not applicable for all situations, and depending on the elements of interest and the research questions involved, an alternative is needed. For determining larval or juvenile rearing environments, solution- based, whole otolith analysis of the larval or juvenile otoliths provides an integrated sample of the rearing environment and has been widely used (e.g. Begg et al. 1998, Thorrold et al. 1998, Gillanders \& Kingsford 2000). Additionally, if low concentration otolith elemental chemistry is of interest, whole otoliths are necessary to provide enough material to meet detection limits.

Stable isotopes of various elements (primarily carbon, oxygen, sulfur, and strontium) have been shown to correlate with the physical and chemical properties of the water that fish inhabit, and with the growth and metabolism of those fish (e.g. Campana 1999). Due to their relative abundance in fish otoliths, measurements of carbon and oxygen isotopes have been increasingly used in ecological studies. Carbon isotope ratios $\left(\delta^{13} \mathrm{C}\right)$ 
are partially controlled by ambient water conditions and partially controlled by fish diet and metabolism (Kalish 1991, Thorrold et al. 1997, Høie et al. 2003). Carbon isotope values of otoliths have been useful in determining fish diet, metabolism, and trophic position (e.g. Schwarcz et al. 1998, Weidman \& Millner 2000, Wurster \& Patterson 2003). Conversely, oxygen isotope ratios $\left(\delta^{18} \mathrm{O}\right)$ have been shown to vary with ambient water conditions and temperature, independent of diet and metabolism (Patterson et al. 1993, Thorrold et al. 1997, Høie et al. 2003). Using micromilling and other fine-scale techniques, $\delta^{18} \mathrm{O}$ ratios in otoliths have been used to develop thermal histories of contemporary (e.g. Kalish 1991, Thorrold et al. 1997), archeologic (e.g. Devereux 1967, Patterson et al. 1993, Patterson 1998, Wurster \& Patterson 2001), and geologic aged fishes (e.g. Patterson 1999, Carpenter et al. 2003).

As a complement to stable isotope analysis, trace element analysis of fish otoliths relies on the same assumptions. Many minor and trace elements in fish otoliths have been found to reflect the physical and chemical characteristics of the water the fish inhabits (Campana 1999). Otolith elemental composition has shown potential in a large variety of applications including, stock discrimination/identity (e.g. Begg et al. 1998, Dove \& Kingsford 1998), saltwater/freshwater migrations (Secor 1992), life history characteristics (Kalish 1990), differentiation of nursery habitats (Gillanders \& Kingsford 2000), and as natural tags (Campana et al. 2000).

All of these otolith chemical analyses are based on 2 primary assumptions: (1) otolith material is retained from the time it is formed, not resorbed or reconstituted over time, and (2) otolith growth is continuous throughout the lifetime of a fish (Campana \& Nielsen 1985, Campana 1999). A third, less explicit, assumption is that any otolith from an individual fish would yield the same result, but do the sagitta and lapillus yield similar signatures for solution-based chemical analyses? We address this question using stable isotopic analysis of carbon and oxygen in paired sagittae and lapilli of juvenile spotted seatrout Cynoscion nebulosus.

One possible key to predicting whether different otoliths can be substituted lies in their comparative growth. If a fish is exposed to inconstant conditions and the lapillus and sagitta grow at different rates, then they may yield different total measures of isotopic and trace element composition. In many fish species, the sagitta and lapillus are nearly the same size during the larval stage, but the sagitta then grows much more rapidly resulting in a distinct size difference beginning early in the juvenile stage (e.g. David et al. 1994, Morioka \& Machinandiarena 2001). These growth differences, in combination with a changing environ- ment, could lead to differences in chemical composition recovered from solution-based analysis of whole otoliths.

Many otolith chemical techniques destroy the otoliths during analysis. This becomes a problem when multiple chemical techniques are needed as well as a determination of fish age (daily or annual). With only 2 sagittae per fish and 3 or more analyses to perform, sagittal otolith material is quickly exhausted, especially with small otoliths. Faced with this problem, researchers may need to substitute a lapillus for a sagitta in 1 or more of the analyses. Preferably the lapillus could be used for determining age, while the 2 sagittae are used for chemical analyses, but in some species reliable ages cannot be obtained from the lapillus. In this case 1 sagitta must be used for assigning age, and the lapilli may be needed for stable isotope or trace element analysis.

Research to date has focused predominantly on sagittal otoliths. This is likely due to the fact that in most species sagittae are the largest, and hence easiest to acquire. Also, many common techniques (e.g. solution-based ICPMS) require a large amount of material for analysis requiring the larger sagittal otoliths to be used (Thresher et al. 1994, Campana 1999). Because sagittae are so commonly used, some authors fail to indicate which otoliths were analyzed (e.g. Dove \& Kingsford 1998, Gao \& Schwarcz 2001, Shiao \& Hwang 2004), leaving the reader to assume sagittae, or that the otolith being analyzed is unimportant.

Comparison of sagitta and lapillus chemistry, particularly for wild populations, is lacking in the scientific literature. The sole study to date, Chesney et al. (1998) examined strontium concentrations and $\mathrm{Sr} / \mathrm{Ca}$ ratios of juvenile gulf menhaden Brevoortia patronus reared in the lab at various temperatures and salinities that were constant through ontogeny. They reported that lapilli and sagittae gave similar results, both differing from the vateritic asteriscus, but we would expect similar results under constant rearing conditions. Chesney et al. (1998) mention similar results for wild-captured fish, but no data are presented. We have found no published studies that compared $\delta^{13} \mathrm{C}$ or $\delta^{18} \mathrm{O}$ values between different otolith types in juvenile fish, and no studies other than Chesney et al. (1998) comparing trace elements or other isotopes.

The goal of this study was to determine whether the lapillus and sagitta have the same otolith chemistry and whether one can be substituted for the other for chemical analysis in wild-captured fish. Specifically our objectives were to: (1) determine whether sagitta and lapillus had similar isotopic signatures for $\delta^{13} \mathrm{C}$ and $\delta^{18} \mathrm{O}$ in wild-captured juvenile spotted seatrout; (2) quantify the relationship between sagitta and lapillus $\delta^{13} \mathrm{C}$ and $\delta^{18} \mathrm{O}$ values so that comparisons can be 
made between data from both structures, and (3) identify possible causes or mechanisms for differing carbon or oxygen isotopic signatures between the 2 structures.

\section{MATERIALS AND METHODS}

Otolith analyses. Juvenile spotted seatrout were collected from seagrass beds near Tangier Island in the lower Chesapeake Bay in 2002. Collection methods are described in Dorval et al. (2005). Juvenile seatrout used in this study ranged from 35 to $120 \mathrm{~mm}$ standard length (SL) and were considered residents of the seagrass beds (Rooker et al. 1998, Dorval et al. 2005). Each fish was weighed and measured, and both sagittae and lapilli were removed, dried, and stored in individual containers. One sagitta and lapillus from each of 19 randomly selected fish were ground and transformed into fine powder in an agate pestle and mortar cleaned with $10 \% \mathrm{HNO}_{3}$, and rinsed with Milli-Q. The crushed powder was transferred to acid-cleaned vials using acid-washed glass probes. From each sample 60 to $100 \mu \mathrm{g}$ of powder were collected and analyzed using a Micromass IsoPrime automated carbonate analyzer, in dual inlet mode (Stable Isotope Laboratory [SIL], University of Maryland). Samples were spiked with 102\% anhydrous phosphoric acid for $10 \mathrm{~min}$ at $90^{\circ} \mathrm{C}$. Ten otolith samples were sequentially analyzed after the measurement of 5 standard samples. The standards were prepared from limestone. Parameter acquisition was based on the coldfinger mode, leading to a precision of \pm 0.03 and $0.06 \%$ o $(1 \sigma)$ respectively for carbon and oxygen isotopic ratios. After analysis the raw data was corrected for machine drift and reported in \%o Vienna Peedee belemnite (VPDB) using standard $\delta$ notation.

We analyzed sagitta and lapillus growth for a sample of randomly selected fish $(n=55)$ from these same collections in 2002. As a possible correlate to isotopic analysis, shape measurements (length and width) were taken on a sample of paired sagittae and lapilli. Otolith sagittal area (calculated as $\pi \times($ length/2) $\times($ width/2)) was compared between sagittae and lapilli for a range of juvenile fish sizes similar to those used for isotope analysis. While growth in weight would have the most relevance to chemical analyses, these otoliths were too small for accurate weight measurements (lapilli $<100 \mu \mathrm{g}$ ); thus length (or area) was used as a proxy for weight. We did not statistically compare growth between sagitta and lapillus since differences were obvious.

Statistical analyses. A paired $t$-test $(\alpha=0.05)$ was used to determine whether relative differences in $\delta^{13} \mathrm{C}$ and $\delta^{18} \mathrm{O}$ values existed between paired sagittae and lapilli. Since one of our objectives was to allow substi- tution of one otolith for the other, linear least squares regression was then used to further examine the relationship between isotopic values in the sagitta and lapillus. The relationship of sagittae and lapilli stable isotope values with fish size was also analyzed with linear least squares regression. All statistical analyses were performed in S-plus v6.2 for Windows, 2003 (Insightful).

\section{RESULTS}

Stable isotopic signatures of $\delta^{13} \mathrm{C}$ and $\delta^{18} \mathrm{O}$ were significantly different for paired sagittae and lapilli of juvenile spotted seatrout. A paired $t$-test confirmed a mean difference of 2.82 for carbon $(t=33.82$, df $=18$, $\mathrm{p}<0.01)$ and 0.44 for oxygen $(t=9.32, \mathrm{df}=18, \mathrm{p}<0.01)$. The sagitta was enriched in $\delta^{13} \mathrm{C}$ (Fig. 1) and $\delta^{18} \mathrm{O}$ (Fig. 2) relative to the lapillus. Regression of sagittal and lapillar $\delta^{13} \mathrm{C}$ was not significantly different from a $1: 1$ ratio with an offset of 2.82 from lapillus to sagitta $\left(\mathrm{R}^{2}=0.88\right) ; \delta^{13} \mathrm{C}$ for the sagitta is then predicted by the addition of 2.82 to lapillus $\delta^{13} \mathrm{C}$ values. Sagittal $\delta^{18} \mathrm{O}$ was also enriched relative to the lapillus, but to a lesser degree than carbon (Fig. 2), and the relationship was not as clear. There was a poor fit $\left(p=0.043, R^{2}=0.22\right)$ for the regression of sagitta $\delta^{18} \mathrm{O}$ on lapillus $\delta^{18} \mathrm{O}$, and the slope was not 1:1.

Sagitta and lapillus of spotted seatrout have distinctly different growth rates. While the 2 otoliths are a similar size at formation, the sagitta grows much faster,

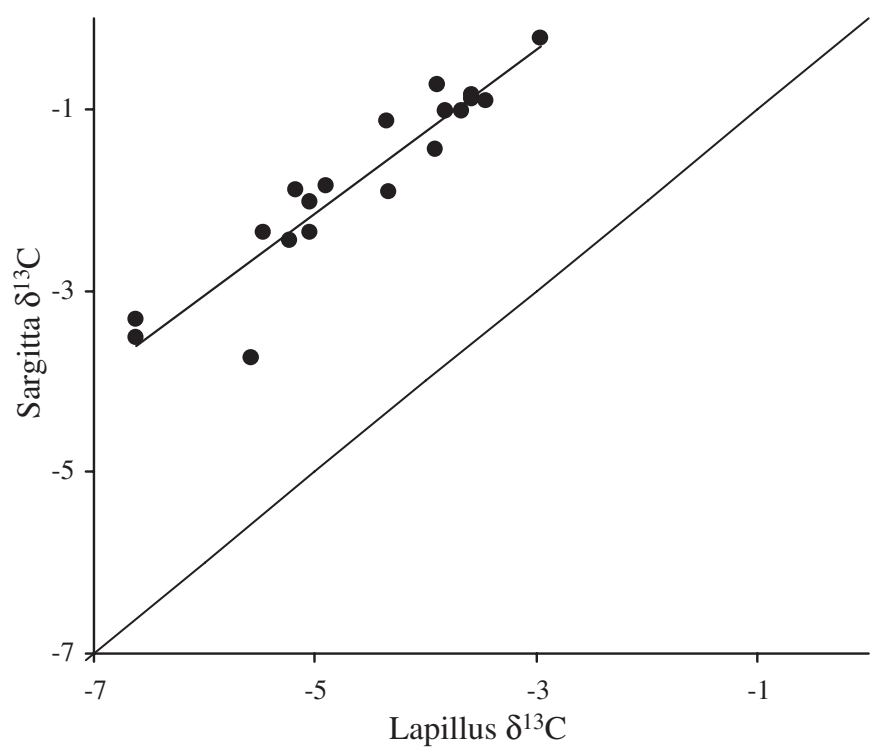

Fig. 1. Cynoscion nebulosus. $\delta^{13} \mathrm{C}$ signatures for paired sagittae and lapilli of juvenile spotted seatrout. Fitted line $(y=$ $0.90 x+2.36)$ is the result of linear regression of sagitta on lapillus $\left(\mathrm{R}^{2}=0.88\right)$ 
and quickly outgrows the lapillus (Fig. 3). In terms of otolith sagittal area (Fig. 4), the size difference is minor when seatrout are $<20 \mathrm{~mm} \mathrm{SL}$, but rapidly increases as the fish become larger. For the lapillus, growth was linear (lapillus area $=0.006 \times \mathrm{SL}-0.056 ; \mathrm{p}<0.001, \mathrm{R}^{2}=$

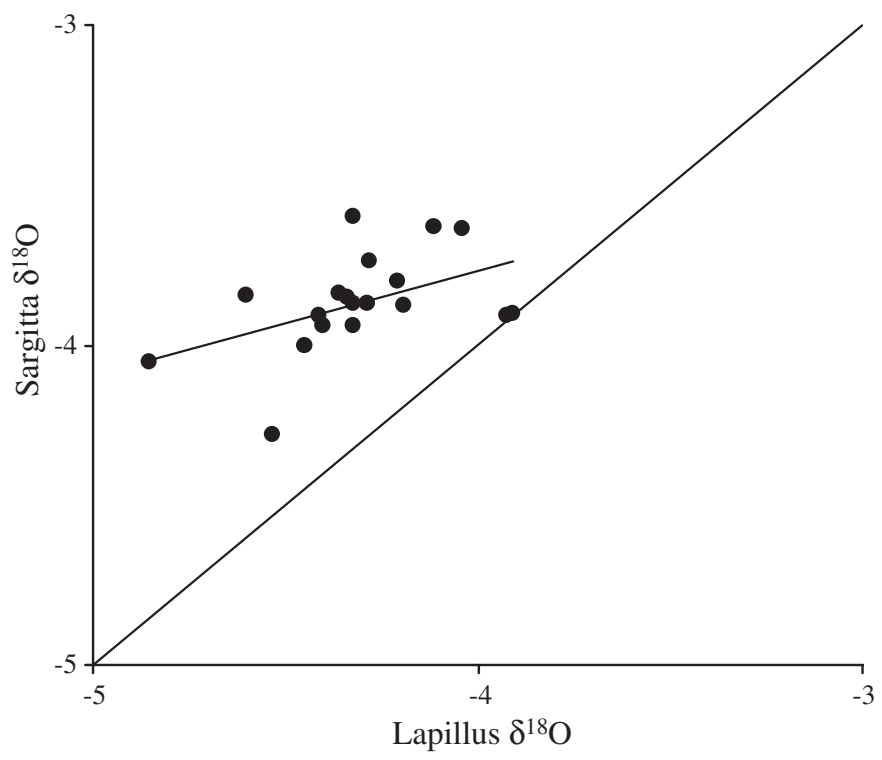

Fig. 2. Cynoscion nebulosus. $\delta^{18} \mathrm{O}$ signatures for paired sagittae and lapilli of juvenile spotted seatrout. Fitted line $(y=$ $0.33 x-2.12)$ is the result of linear regression of sagitta on lapillus $\left(R^{2}=0.22\right)$

\section{Lapillus}

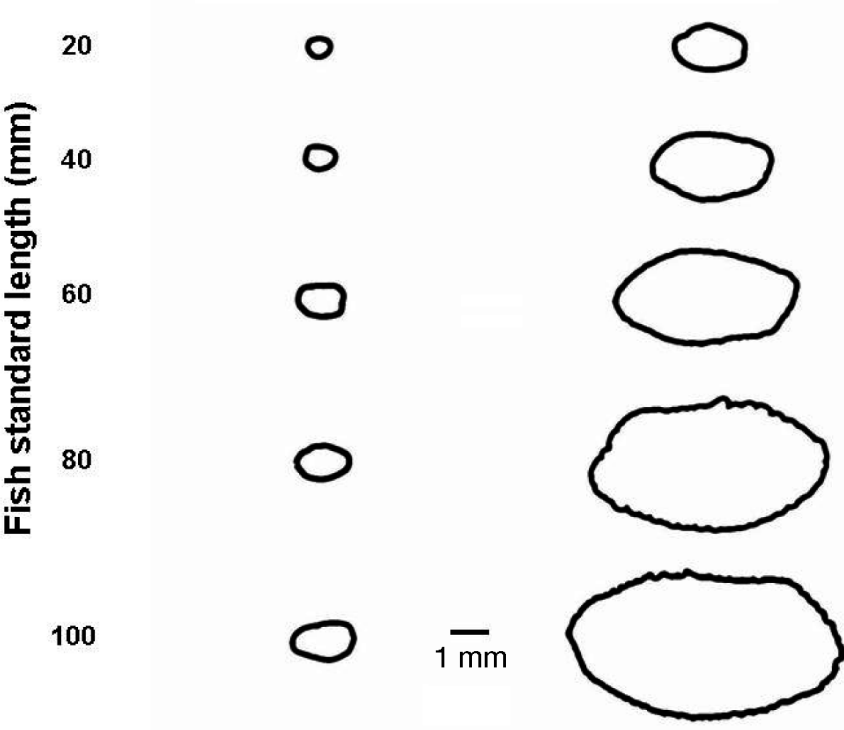

Fig. 3. Cynoscion nebulosus. Line diagram depicting relative size of lapillus and sagitta for juvenile spotted seatrout at a range of fish lengths. Size differences between the 2 otoliths are minor in fish $<20 \mathrm{~mm}$ but rapidly become more pronounced as the fish get larger
0.98) with a slope of $0.006 \mathrm{~mm}^{2}$ per $\mathrm{mm}$ of fish SL. Sagittae however, followed a power function (sagitta area $=0.004 \times \mathrm{SL}^{1.805} ; \mathrm{p}<0.001, \mathrm{R}^{2}=0.96$ ) and quickly outgrew the lapillus with increasing fish size.

The relationship between stable isotope values and fish length represents the interaction of environmental history and integrated otolith growth. There was a significant positive relationship between otolith $\delta^{13} \mathrm{C}$ and fish length in both sagitta $\left(p<0.002, R^{2}=0.48\right)$ and lapillus ( $<<0.002, \mathrm{R}^{2}=0.49$ ) (Fig. 5). The regression of $\delta^{13} \mathrm{C}$ on fish length explains nearly $50 \%$ of the varia-

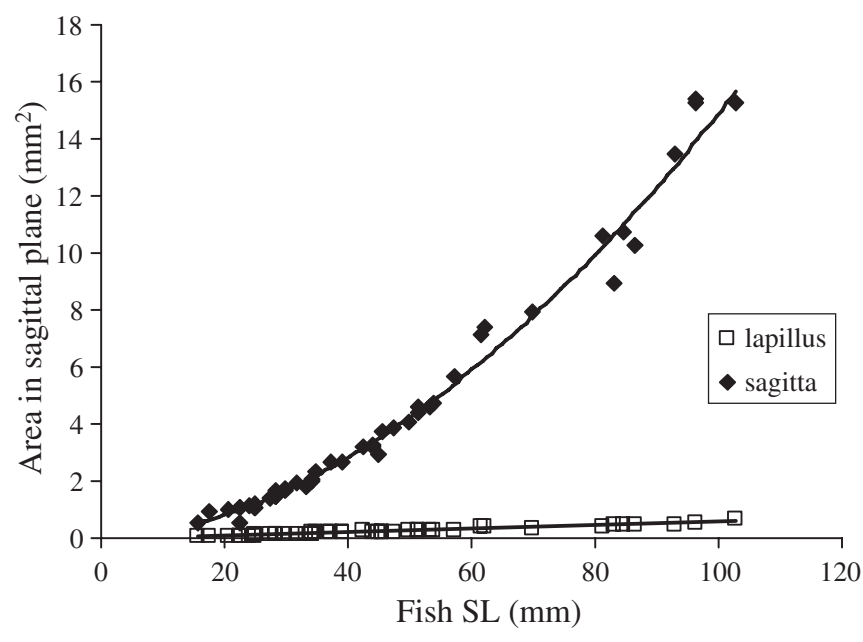

Fig. 4. Cynoscion nebulosus. Comparison of otolith growth in sagittal area between lapillus and sagitta for juvenile spotted seatrout. Weight measures for these small otoliths are unstable and difficult to obtain so we used area as a proxy. Lapillus $(\mathrm{n}=48)$ growth was best fit with a linear model (lapillus area $=$ $0.006 \times$ standard length [SL] $-0.056 ; \mathrm{p}<0.001, \mathrm{R}^{2}=0.98$ ) while sagittal $(\mathrm{n}=49)$ growth followed a power function (sagitta area $\left.=0.004 \times \mathrm{SL}^{1.805} ; \mathrm{p}<0.001, \mathrm{R}^{2}=0.96\right)$

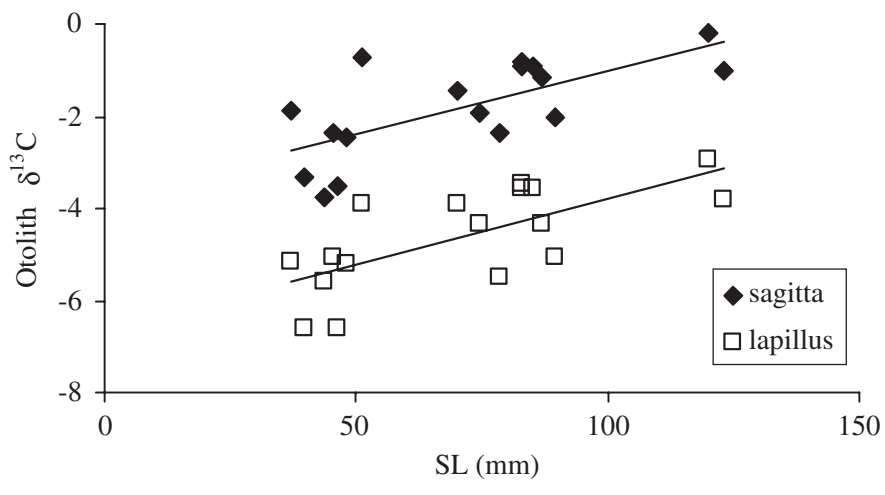

Fig. 5. Cynoscion nebulosus. Comparison of sagitta and lapillus $\delta^{13} \mathrm{C}$ values vs. fish standard length (SL). Both sagitta ( $\mathrm{p}<$ $\left.0.002, R^{2}=0.48\right)$ and lapillus $\left(p<0.002, R^{2}=0.49\right) \delta^{13} C$ values were positively correlated with SL. The slopes were similar for both otoliths, indicating that differences between sagittae and lapilli $\delta^{13} \mathrm{C}$ values were largely influenced by metabolism 


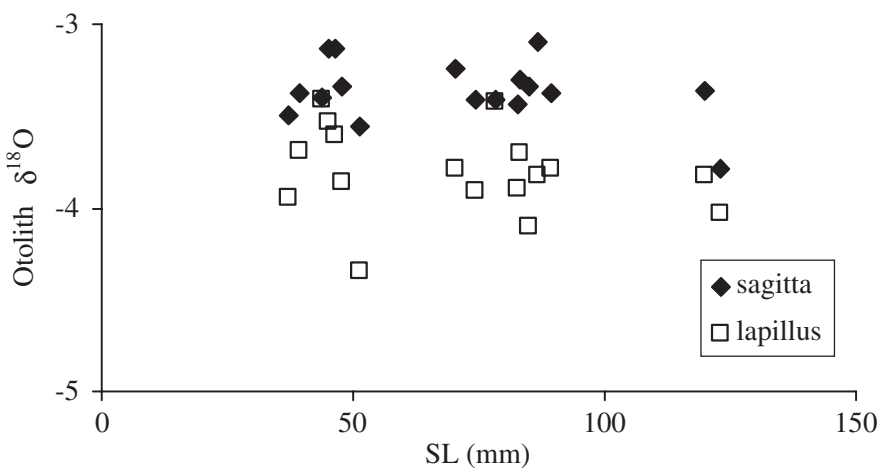

Fig. 6. Cynoscion nebulosus. Comparison of sagitta and lapillus $\delta^{18} \mathrm{O}$ values vs. fish standard length (SL). There was no relationship between SL and otolith $\delta^{18} \mathrm{O}$ for either sagittae or lapilli, indicating that differences are not driven by metabolism, rather the interaction of environment and otolith growth

tion, suggesting a high contribution of metabolic carbon to the otoliths. The slope of the relationship was similar for sagitta and lapillus suggesting that otolith growth differences were not likely the cause of differences in sagitta and lapillus $\delta^{13} \mathrm{C}$. For oxygen, which is not affected by fish metabolism and growth, there was no relationship between otolith $\delta^{18} \mathrm{O}$ and fish length in either the sagitta $(p=0.25)$ or lapillus ( $p=0.38)$ (Fig. 6). $\delta^{18} \mathrm{O}$ values for the sagitta and lapillus are apparently independent of fish growth and presumably due to the interaction of the environment and otolith growth.

\section{DISCUSSION}

This study is unique in its examination of chemical differences between the sagitta and lapillus of wildcaptured juvenile fish. Chesney et al. (1998) reported similar strontium concentrations in lapilli and sagittae of Gulf menhaden, raised in the laboratory. This would be expected, since differences in growth rates of the structures would be nullified by the constant rearing environment. Meyer-Rochow et al. (1992) suggested differences in sagittal and lapillar stable isotope chemistry of adult New Zealand mullet Mugil cephalus, but issues with a small sample size and improper statistical analysis led to problematic results which were not clearly interpretable. Our spotted seatrout otoliths show clear differences between the sagitta and lapillus in both $\delta^{13} \mathrm{C}$ and $\delta^{18} \mathrm{O}$. Our initial hypothesis was that these differences were due to the interaction of a variable environment and differing growth rates of the 2 structures. Because of the integrated nature of solution-based analyses, fish exposed to environmental variation during their life history may exhibit different chemical properties in the sagitta and lapillus simply due to differences in otolith growth. Since sagittal growth is much faster subsequent to initial formation, whole otolith analysis will be biased toward the most recent material deposited, and in turn the most recent water conditions. Because lapillus growth is linear, the lapillus will provide an integrated sample of the fish's environmental history prior to capture, making it a better indicator of larval conditions.

Recognizing that the sagitta and lapillus grow at different rates is one key to understanding the differing results of solution-based chemical analysis in the 2 otoliths. As is characteristic of sciaenids, spotted seatrout sagittae attain a much larger size than lapilli. This growth difference becomes apparent in the early juvenile stage with size differences increasing over time. The precise relationship between sagitta and lapillus growth is species specific, but the general pattern of faster sagittal growth is common (Campana 2004). The integrated nature of solution-based analysis results in different concentrations of $\delta^{13} \mathrm{C}$ and $\delta^{18} \mathrm{O}$ for the 2 whole otoliths.

We expected that after detrending the isotope data to account for fish length, and thus differences in otolith size, relationships would become clearer. Surprisingly, this was not the case for either $\delta^{13} \mathrm{C}$ or $\delta^{18} \mathrm{O}$. A significant correlation was observed between fish length and otolith $\delta^{13} \mathrm{C}$ values which was similar for both sagittae and lapilli. Because a portion of otolith $\delta^{13} \mathrm{C}$ is controlled by diet and metabolism (Kalish 1991, Høie et al. 2003), we would expect fish size to affect otolith $\delta^{13} \mathrm{C}$ through metabolic processes. The metabolic contribution of carbon to fish otoliths varies seasonally, and could be expected to be the primary carbon source during the juvenile stage or when fish growth is rapid (i.e. Wurster \& Patterson 2003, Wurster et al. 2005). The similar relationship for sagittae and lapilli with fish length argues for a strong influence of metabolic carbon, obscuring any effect of otolith growth. The offset between $\delta^{13} \mathrm{C}$ signatures for sagittae and lapilli is likely determined by internal processes and differences between the 2 otoliths in uptake of metabolic carbon. Oxygen, on the other hand, has no internal control and is dependent on external factors such as temperature and $\delta^{18} \mathrm{O}$ of water (Patterson et al. 1993, Thorrold et al. 1997, Høie et al. 2004). We found no relationship between fish length and otolith $\delta^{18} \mathrm{O}$ in sagittae or lapilli. This relationship between fish growth and otolith $\delta^{18} \mathrm{O}$ was likely obscured by the effects of the variable environment to which these fish were exposed.

Although our results clearly show a difference between sagitta and lapillus chemistry, we were unable to separate the interactive effects of otolith growth and a changing environment. Otolith $\delta^{18} \mathrm{O}$ values are derived from the $\delta^{18} \mathrm{O}$ value of water and the tempera- 
ture at the time of formation (Patterson et al. 1993, Thorrold et al. 1997, Høie et al. 2004). While temperature profiles are available for the seagrass beds where these spotted seatrout were captured, we do not have site specific $\delta^{18} \mathrm{O}$ values of the water in the beds. Previous research has indicated possible differences in the baseline $\delta^{18} \mathrm{O}$ values of water across the Bay (Dorval et al. 2005). Due to the inherent variability of natural systems, evaluating the interaction of otolith growth and changing environment is exceedingly complicated with wild-captured fish and would be better suited to a controlled laboratory environment.

Our results are applicable to any solution-based method, but continuing advances in technology and analysis methods provide finer scale measurements that should better characterize differences between sagittal and lapillar chemistry. For stable isotopes, micromilling of otoliths can provide much finer scale sampling than whole otolith solution methods (Wurster \& Patterson 1999) and should show similar results for oxygen in the sagitta and lapillus assuming equivalent sampling of growth bands. For example if it were possible to mill out the Day 20 to 25 growth band on the sagitta and lapillus, we would assume the resulting $\delta^{18} \mathrm{O}$ chemistry would be similar. This requires that the same time period must be recovered from each otolith although the period will be represented by different amounts of material for the sagitta or lapillus. Conversely, a standard milled sample of a particular weight would encompass a different number of days depending on which otolith was used. Similarly, several other techniques have been used (e.g. LA-ICPMS, electron microprobe, proton induced X-ray emission) (Secor 1992, Secor et al. 1995, Campana et al. 1997) that can provide chemical signatures for various elements on a much finer scale than whole otolith solution-based analysis. However, these approaches are not useful for distinguishing some trace elements such as rare-earth elements (Dorval et al. 2005) that are found in ppm or ppt. For elements abundant enough to be measured by these analyses, signatures of individual growth bands would be expected to be similar for sagittae and lapilli.

As chemical analysis of fish otoliths becomes more widespread, it is important that researchers consider the importance of choosing the sagitta or lapillus for solution-based analysis. Depending on what questions are being addressed, either the sagitta or lapillus may be more appropriate. For example, the lapillus may be better for determining natal origin because the early natal signature is less obscured by more recent growth. Alternatively, the sagitta would be more appropriate for distinguishing post-settlement nursery areas due to the increased influence of more recent otolith material. In either case, researchers need to be aware of the influence of otolith growth rate on the resulting chemical signatures from solution-based whole otolith analysis and consider that, in terms of whole otolith chemistry, sagittae $\neq$ lapilli.

Acknowledgements. We thank Mr. D. Combs, Dr. E. Dorval, and Dr. J. van Monfrans, whose assistance in the field was invaluable. We thank Dr. J. Kaufman of the University of Maryland for his assistance with stable-isotope analysis. This project was funded by Virginia Sea Grant (R-CF-42) and NSF (OCE 05-25964) to C.M.J.

\section{LITERATURE CITED}

Begg GA, Cappo M, Cameron DS, Boyle S, Sellin MJ (1998) Stock discrimination of school mackerel, Scomberomorus queenslandicus, and spotted mackerel, Scomberomorus munroi, in coastal waters of eastern Australia by analysis of minor and trace elements in whole otoliths. Fish Bull (Wash, DC) 96:653-666

Campana SE (1999) Chemistry and composition of fish otoliths: pathways, mechanisms, and applications. Mar Ecol Prog Ser 188:263-297

Campana SE (2004) Photographic atlas of fish otoliths of the northwest Atlantic Ocean. Can Spec Publ Fish Aquat Sci 133

Campana SE, Neilson JD (1985) Microstructure of fish otoliths. Can J Fish Aquat Sci 42:1014-1032

Campana SE, Thorrold SR, Jones CM, Gunther D and 15 others (1997) Comparison of accuracy, precision, and sensitivity in elemental assays of fish otoliths using the electron microprobe, proton-induced X-ray emission, and laser ablation inductively coupled plasma mass spectrometry. Can J Fish Aquat Sci 54:2068-2079

Campana SE, Chouinard GA, Hanson JM, Frechet A, Brattey $\mathrm{J}$ (2000) Otolith elemental fingerprints as biological tracers of fish stocks. Fish Res 46:343-357

Carpenter SJ, Erickson JM, Holland FD Jr (2003) Migration of late Cretaceous fish. Nature 423:70-74

Chesney EJ, McKee BM, Blanchard T, Chan LH (1998) Chemistry of otoliths from juvenile menhaden Brevoortia patronus: evaluating strontium, strontium:calcium and strontium isotope ratios as environmental indicators. Mar Ecol Prog Ser 171:261-273

David AW, Isely JJ, Grimes CB (1994) Differences between the sagitta, lapillus, and asteriscus in estimating age and growth in juvenile red drum, Sciaenops ocellatus. Fish Bull (Wash, DC) 92:509-515

Devereaux I (1967) Temperature measurements form oxygen isotope ratios of fish otoliths. Science 155:1684-1685

Dorval E, Jones CM, Hannigan R, van Monfrans J (2005) Can otolith chemistry be used for identifying essential seagrass habitats for juvenile spotted seatrout, Cynoscion nebulosus, in Chesapeake Bay. Mar Freshw Res 56:645-653

Dove SG, Kingsford MJ (1998) Use of otoliths and eye lenses for measuring trace-metal incorporation in fishes: a biogeographic study. Mar Biol 130:377-387

Gao Y, Schwarcz HP (2001) Seasonal stable isotope records of otoliths from ocean-pen reared and wild cod, Gadus morhua. Environ Biol Fish 61:445-453

Gillanders BM, Kingsford MJ (2000) Elemental fingerprints of otoliths of fish may distinguish estuarine 'nursery' habitats. Mar Ecol Prog Ser 201:273-286

Høie H, Folkvord A, Otterlei E (2003) Effect of somatic and otolith growth rate on stable isotopic composition of early 
juvenile cod (Gadus morhua L.) otoliths. J Exp Mar Biol Ecol 289:41-58

Høie H, Otterlei E, Folkvord A (2004) Temperaturedependent fractionation of stable oxygen isotopes in otoliths of juvenile cod (Gadus morhua L.). ICES J Mar Sci 61:243-251

Kalish JM (1990) Use of otolith microchemistry to distinguish the progeny of sympatric anadromous and non-anadromous salmonids. Fish Bull (Wash, DC) 88:657-666

Kalish JM (1991) Oxygen and carbon isotopes in the otoliths of wild and laboratory-reared Australian salmon (Arripis trutta). Mar Biol 110:37-47

Meyer-Rochow VB, Cook I, Hendy CH (1992) How to obtain clues from the otoliths of an adult fish about the aquatic environment it has been in as a larva. Comp Biochem Physiol 103A:333-335

Morioka S, Machinandiarena L (2001) Comparison of daily increment formation pattern between sagittae and lapilli of ling (Genypterus blacodes) larvae and juveniles collected off Argentina. N Z J Mar Freshw Res 35:111-119

Patterson WP (1998) North American continental seasonality during the last millennium: high-resolution analysis of sagittal otoliths. Palaeogeogr Palaeoclimatol Palaeoecol 138:271-303

Patterson WP (1999) Oldest isotopically characterized fish otoliths provide insight to Jurasic continental climate of Europe. Geology 27:199-202

Patterson WP, Smith GR, Lohmann KC (1993) Continental paleothermometry and seasonality using the isotopic composition of aragonitic otoliths of freshwater fishes. Geophys Monogr 78:191-202

Rooker JR, Holt SA, Soto MA, Holt GJ (1998) Postsettlement patterns of habitat use by sciaenid fishes in subtropical seagrass meadows. Estuaries 21:318-327

Schwarcz HP, Gao Y, Campana S, Browne D, Knyf M, Brand U (1998) Stable carbon isotope variations in otoliths of Atlantic cod (Gadus morhua). Can J Fish Aquat Sci 55: 1798-1806

Secor DH (1992) Application of otolith microchemistry analysis to investigate anadromy in Chesapeake Bay striped bass Morone saxatillis. Fish Bull (Wash, DC) 90:798-806

Editorial responsibility: Howard I. Browman (Associate Editor-in-Chief), Storebø, Norway
Secor DH, Henderson-Arzapalo A, Piccoli PM (1995) Can otolith microchemistry chart patterns of migration and habitat utilization in anadromous fishes? J Exp Mar Biol Ecol 192:15-33

Shiao JC, Hwang PP (2004) Thyroid hormones are necessary for teleostean otolith growth. Mar Ecol Prog Ser 278: $271-278$

Thorrold SR, Campana SE, Jones CM, Swart PK (1997) Factors determining $\delta^{13} \mathrm{C}$ and $\delta^{18} \mathrm{O}$ fractionation in aragonitic otoliths of marine fish. Geochim Cosmochim Acta 61: 2909-2919

Thorrold SR, Jones CM, Campana SE, McLaren JW, Lam JWH (1998) Trace element signatures in otoliths record natal river of juvenile American shad (Alosa sapidissima). Limnol Oceaogr 43:1826-1835

Thresher RE, Proctor CH, Gunn JS, Harrowfield IR (1994) An evaluation of electron-probe microanalysis of otoliths for stock delineation and identification of nursery areas in a southern temperate groundfish, Nemadactylus macropterus (Sheilodactylidae). Fish Bull (Wash, DC) 92:817-840

Weidman CR, Millner R (2000) High-resolution stable isotope records from North Atlantic cod. Fish Res 46:327-342

Wurster CM, Patterson WP (1999) Advances in micromilling techniques: a new apparatus for acquiring high-resolution oxygen and carbon stable isotope values and major/minor elemental ratios from accretionary carbonate. Comput Geosci 25:1155-1162

Wurster CM, Patterson WP (2001) Late Holocene climate change for the eastern interior United States: evidence from high-resolution $\delta^{18} \mathrm{O}$ values of sagittal otoliths. Palaeogeogr Palaeoclimatol Palaeoecol 170:81-100

Wurster CM, Patterson WP (2003) Metabolic rate of late Holocene freshwater fish: evidence from $\delta^{13} \mathrm{C}$ values of otoliths. Paleobiology 29:492-505

Wurster CM, Patterson WP, Stewart DJ, Bowlby JN, Stewart TJ (2005) Thermal histories, stress, and metabolic rates of Chinook salmon (Oncorhynchus tshawytscha) in Lake Ontario: evidence from intra-otolith stable isotope analyses. Can J Fish Aquat Sci 62:700-713

Submitted: August 29, 2005; Accepted: November 5, 2005 Proofs received from author(s): April 10, 2006 